\title{
Estimation of Global Solar Radiation using Pyranometer and NILU-UV Irradiance Meter at Pokhara Valley in Nepal
}

\author{
K. N. Poudyal ${ }^{1}$, B. K. Bhattarai ${ }^{1}$, B. K. Sapkota ${ }^{1}$, Berit Kjeldstad ${ }^{2}$, N. R. Karki ${ }^{2}$ \\ ${ }^{I}$ Department of Engineering Science and Humanities, Institute of Engineering, Central Campus, Pulchowk, \\ Tribhuvan University, Nepal \\ ${ }^{2}$ Department of Physics, Norwegian University of Science and Technology, Norway \\ Corresponding Email: khem.poudyal@yahoo.com
}

\begin{abstract}
The global solar radiation (GSR) and cloud transmittance factor (cf) are measured at the horizontal surface since 2009 using calibrated CMP6 Pyranometer and NILUUV Irradiance Meter at Pokhara $\left(28.22^{\circ} \mathrm{N}, 83.32^{\circ} \mathrm{E}\right)$ which is about $800 \mathrm{~m}$ from the sea level lying just $20 \mathrm{~km}$ south of the Himalayas. This paper explains the daily, monthly and seasonal variation of global solar radiation and also compared with temperature and rainfall to global solar radiation. The annual average daily global solar radiation is about $4.81 \mathrm{kWh} / \mathrm{m}^{2} /$ day which is sufficient to promote solar active and passive solar energy technology at sub-Himalaya terrain Pokhara and other similar geographical locations. The correlation coefficient 0.70 is found in between clearness index $(\mathrm{K})$ and cloud transmittance factor $(\mathrm{cf})$. This novel result can be used for location of similar meteorological and geographical characteristics at which solar data are not available.
\end{abstract}

Keywords: solar radiation, variation factors, clearness factor, cloud transmittance factor, correlation coefficient.

\section{Introduction}

The knowledge of global solar radiation is essential for the optimal design and the prediction of the system performance in solar energy conversion systems [1]. The solar radiation data are the fundamental inputs for design, optimization and performance evaluation of solar technologies and applications such as photovoltaic and solar thermal systems for any specific location. Unfortunately, for many developing countries including Nepal, solar radiation measurements are not readily available because of high cost associated with acquiring the solar irradiance data. In this regard, it is necessary to develop the best methods or appropriate models to find out the accurate data of global solar radiation [2]. The national average sunshine hours and solar insolation are $6.8 /$ day and $4.7 \mathrm{kWh} / \mathrm{sq} . \mathrm{m} /$ day respectively. However the energy scenario of Nepal is alarming situation because of 4 hours to 16 hours loads shedding per day at rainy season and dry season respectively [3].

The study of solar radiation should incorporate solar radiation and local weather condition. The total solar radiation potential will be key parameter for designing and predicting the performance of solar energy equipment and solar energy potential [4]. It has been verified that the higher the altitude greater the total solar radiation under the clear and intermediate sky conditions, but under the overcast days the solar radiation is very low in comparison with sunny days [5]. The solar radiant energy on the earth's surface is a requirement not only in the studies of climate change, environmental pollution but also in agriculture, hydrology, food industry and promotion of overall solar energy technology programs [6]. 
National Renewable Energy Laboratory (NREL), USA solar map report shows that there is about equal amount solar radiation is found at throughout the country ranging from 4.5-5 $\mathrm{kWh} / \mathrm{m} 2 /$ day. However at the North Western Region of Nepal the radiation is about 6-6.5 $\mathrm{kWh} / \mathrm{m} 2 /$ day as derived from Solar Resource Satellite DLR. The DLR and NREL solar resource maps are compared with the measured data at three sites [7]. The relative variation of the model data with the measured data is analyzed considering point to point as well as region to region on monthly and annual basis and it is observed that within a particular point of location, DLR satellite data varies less than the NREL data.

It is necessary to develop the authentic data base for modeling and also investigate the solar active and passive energy application in Nepal which will be milestone for the industrial, tourism, trade, communication, education, modern agriculture and public health issues. In spite of this, it will be used to study the impacts on human health, solar energy budget, climate change, global warming and impacts on agriculture production in the long run [8].

It is known that the higher the altitude greater the total solar irradiance under the clear and intermediate sky conditions, but under the overcast days the solar irradiance is very low in comparison with sunny days. The solar radiation increases with increase in altitude mainly due to decreasing amounts of air molecules, ozone, aerosols and clouds in high altitude atmosphere. Actually, mapping the solar radiant energy on the earth's surface is a requirement not only in the studies of climate change, ecosystems, environmental pollution but also in agriculture, hydrology, food industry and non conventional energy development programs [9].

The utilization of solar energy, like any other natural resource, requires detailed information on availability. Since solar radiation reaching the Earth's surface depends on many factors which are not global character, a study of solar radiation under local weather conditions is also essential. This study is aimed at providing more information about the total solar radiation potential which will be milestone for designing and predicting the performance of solar energy equipment and solar energy potential [5].

The global solar radiation is affected by clouds, water vapor, aerosols, ozone, and other gases. The cloud is the key affecting factor of solar radiation. Actually the water vapor varies during day and seasonal variation. Thus there is more water vapor is found at wet season than at dry season. There is not only parameters mentioned above affect the amount of solar radiation arriving at the earth surface, but also the incident angle of solar radiation. This angle varies with time, season and location. The geographical distribution of solar radiation over a region is normally different from other regions due to the position and atmospheric constituents of the local weather condition [10].

Cloud is primarily responsible for the fluctuating intensity of sunshine hours on the ground surface. The variation, however, is not due to the angle of incidence of the sun's rays with ground surface and its azimuth [11].

The cloud transmittance factor (cf) is the ratio of measured radiation to the calculated clear sky radiation no aerosols, zero surface albedo. It is measured in percentage.

The main aim of this study is to estimate the global solar radiation using the cloud transmittance factor (cf) and clearness factor (KT) [12] .This paper explains a method to find out the trend of monthly and seasonal variation of global solar radiation at high mountain with complex terrain 
where there is no other viable alternatives for energy which is essential for the tourism industry as well as local consumption.

\section{Study Area}

Pokhara is a remarkable place of natural beauty. It is situated at an altitude of $800.0 \mathrm{~m}$ from the sea level and $150.0 \mathrm{~km}$ west of capital Kathmandu. The elevation rises from $1000.0 \mathrm{~m}$ to over $7500.0 \mathrm{~m}$ over a span of $20.0 \mathrm{~km}$. As a result of this sharp rise in altitude, the Pokhara region has one of the highest precipitation rates in the country $(3350 \mathrm{~mm} / \mathrm{year}$ in the valley to $5600 \mathrm{~mm} /$ year in Lumle). The climate of this city is sub-tropical; however, the elevation keeps the temperatures moderate: the summer temperatures average between 25 to $35^{\circ} \mathrm{C}$, in winter around 2 to $15^{\circ} \mathrm{C}$. Summers are humid and mild, most precipitation occurs during the monsoon season (July - September), winter and spring skies are generally clear and sunny.

\section{Instrument and Methods}

The global solar radiation on a horizontal surface was measured using Kipp and Zonen CMP6 Pyranometer and similarly NILU-UV Irradiance Meter measures the cloud transmittance factor at Pokhara. These instruments are installed at Pokhara $\left(28.22^{\circ} \mathrm{N}, 83.32^{\circ} \mathrm{E}\right)$. The figures CMP6 Pyranometer and NILU-UV Irradiance Meter is shown in figure 1.a and Figure $1 \mathrm{~b}$.

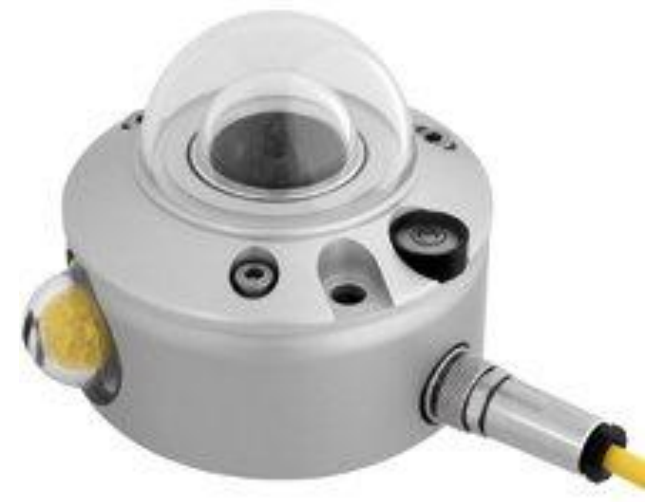

Figure 1.a: CMP6 Pyranometer

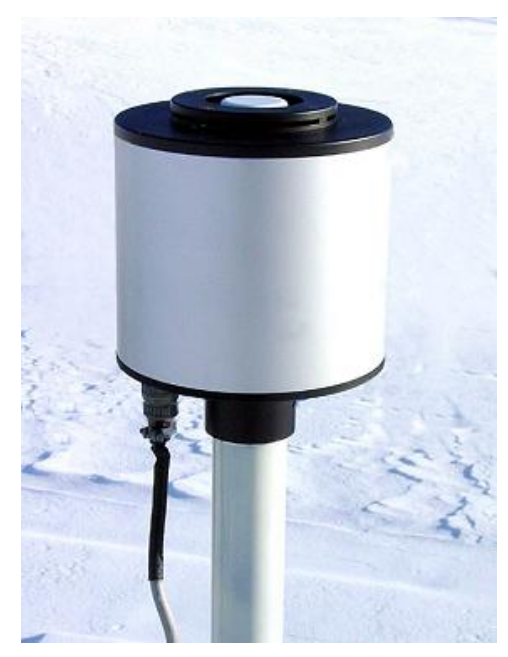

Figure 1.b: NILU-UV Irradiance Meter

The CMP6 Pyranometer has the operating temperature is from $-40^{\circ} \mathrm{C}$ to $80^{\circ} \mathrm{C}$. It has wide spectral range of instrument from $310 \mathrm{~nm}$ to $2800 \mathrm{~nm}$. The sensitivity of instrument and field of view are 5 to $15 \mu \mathrm{V} / \mathrm{W} / \mathrm{m}^{\wedge} 2$ and $180^{\circ}$ respectively. In this instrument, the measuring data is recorded by LOGBOX SD data logger within a minute resolution for 24 hours. Its special features are low noise, high resolution and low power consumption. It works in all weather conditions. It collects the data at real time for the needs of meteorology and slow signal analysis. We can insert the SD memory card for long term data storage. For the communication LOGBOX uses either RS232 or RS485 communication port [13]. 
The cloud transmittance factor (cf) is measured by sophisticated NILUUV irradiance meter. This device is a six channel radiometer designed to measure hemispherical solar UV irradiances as well as cloud transmittance factor on a plane surface. The different effects of cloud on global solar radiation and UV radiation are estimated on the basis of cloud transmittance factor. The measured cf is utilized to explain the availability of solar energy at different places.. It is the ratio of measured global solar radiation to the calculated clear sky solar radiation no aerosols, zero surface albedo. It is measured in percentage. The range of cloud transmittance factor value is from 0 to 1 [14].

The global solar radiation $(\mathrm{Hg})$ is measured using CMP6 Pyranometer on the horizontal surface at Lukla. Similarly the cloud transmittance factor $\mathrm{cf}$ is measured by NILU-UV Irradiance Meter.

However the extraterrestrial global solar radiation $\mathrm{H} 0$ is calculated using equation (1.10.3) [15].

$$
H_{0}=\frac{24}{\pi} I_{s c}\left(1+0.033 \operatorname{Cos} \frac{360}{365} n\right)\left(\omega \frac{\pi}{180} \operatorname{Sin} \phi \operatorname{Sin} \delta+\operatorname{Cos} \phi \operatorname{Cos} \delta \operatorname{Sin} \omega\right)
$$

where $\mathrm{H}_{0}$ is monthly mean of daily global extraterrestrial solar radiation $\left(\mathrm{MJ} / \mathrm{m}^{2} / \mathrm{day}\right), \mathrm{H}_{\mathrm{g}}$ is monthly mean of daily global solar radiation $\left(\mathrm{MJ} / \mathrm{m}^{2} /\right.$ day), $\varphi$ is the latitude (rad) and $\delta$ is the solar declination angle (rad). $\omega$ is sunset hour angle for typical day and $n$ is mean day of each months

where, $\mathrm{n}$ is the day of the year. January first $\mathrm{n}=1$ to 365 days.

$$
\delta(\text { degree })=23.45 \times \sin \left\{\frac{360}{365}(284+n)\right\}
$$

The relation of day length is,

$$
\begin{aligned}
& \text { Day Length }=\frac{2}{15} \times \cos ^{-1}(-\tan \varphi \times \tan \delta) \\
& \omega=\cos ^{-1}(-\tan \varphi \times \tan \delta)
\end{aligned}
$$

where, $\omega$ is the sunset hour angle

In this paper we compare the daily, monthly and seasonal variation of global solar radiation using the clearness index and cloud transmittance factor. The use of these two coefficient factors, we can found the coefficient of determination. On the basis of $\mathrm{R}^{2}$, the $\mathrm{H}_{\mathrm{g}} / \mathrm{H}_{0}$ can be found using the linear equation and after applying the equation (1) for the extraterrestrial global solar radiation is found. At the end $\mathrm{H}_{\mathrm{g}}$ can be calculated which will be novel work in our fast changing weather in the sub-Himalaya region where all types of measuring instruments cannot be installed.

\section{Results and Discussion}

\subsection{Daily Variation of Global Solar Radiation in Pokhara}

The diurnal variation of global solar radiation varies due to inclination, solar zenith angle, and change in season and local weather conditions. Figure 2 shows the daily variation of global solar radiation at the measurement site. The maximum solar radiation is found to be $28.86 \mathrm{MJ} / \mathrm{m}^{2} /$ day on $4^{\text {th }}$ of June. 


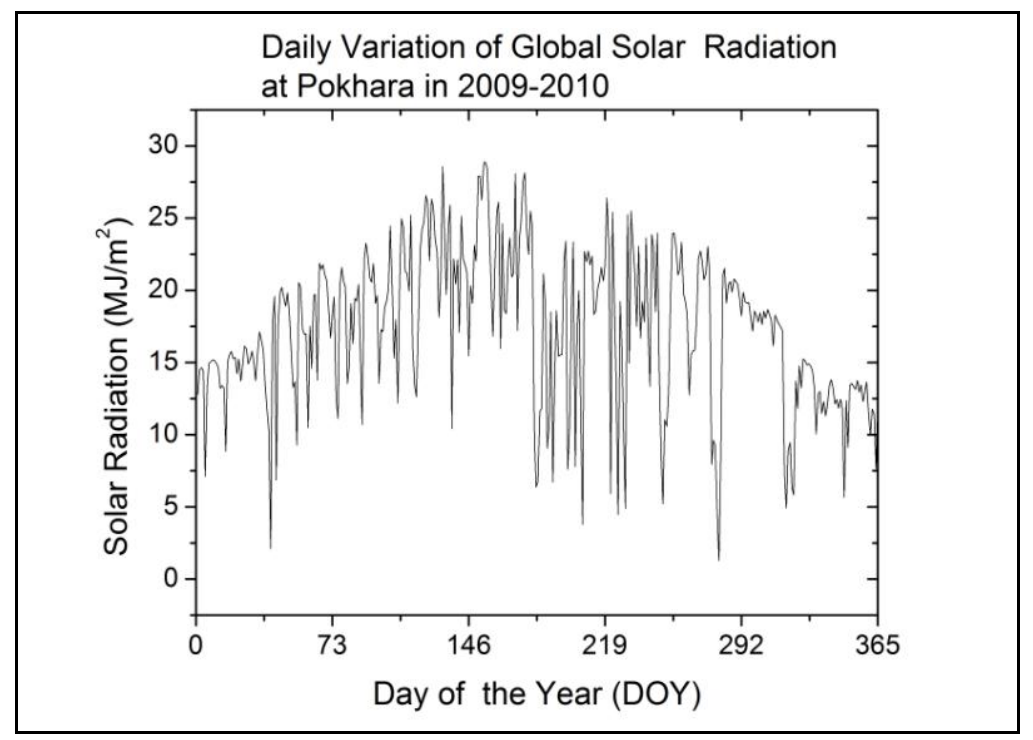

Figure 2: Daily Variation of Global Solar Radiation in 2009-2010

\subsection{Monthly Variation of Global Solar Radiation}

Figure 3 shows the trend of measured and extra terrestrial global solar radiation are very much similar. However there was maximum solar radiation $23.21 \mathrm{MJ} / \mathrm{m}^{2} /$ day is found in the month of June. The maximum variation in measured value and calculated value is $55 \%$ percent in the month of July with the measured value being in the lower side. Hence statistical analysis indicates that the measured data are relevant as well as sufficient to explore the solar energy even in December when GSR is $12.04 \mathrm{MJ} / \mathrm{m}^{2} /$ day.

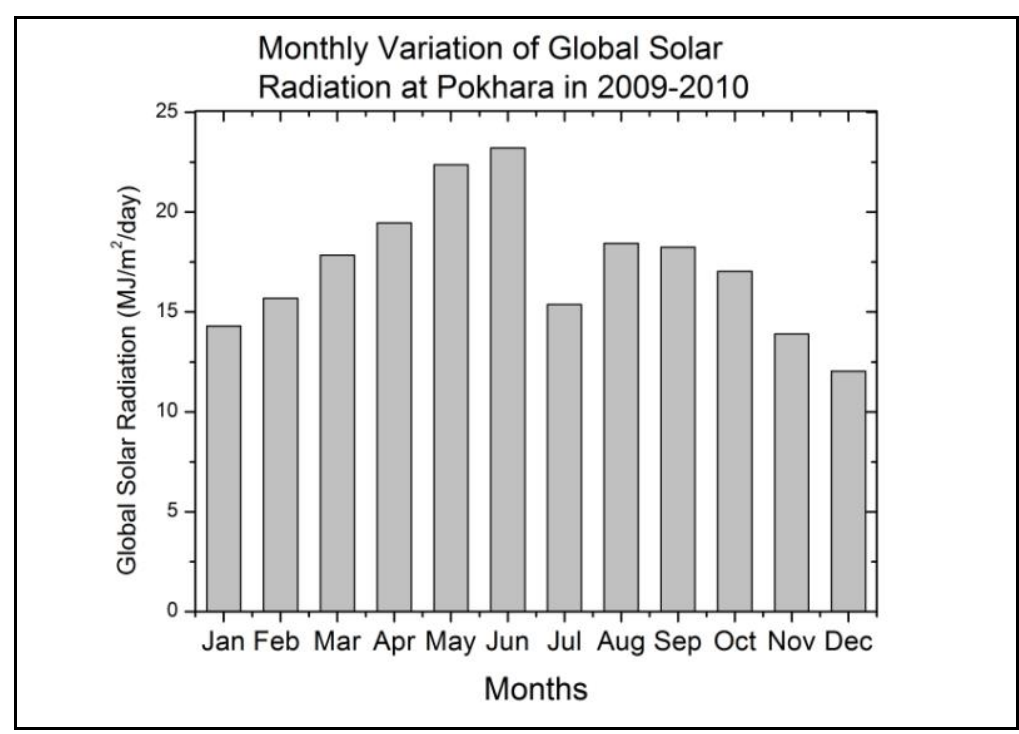

Figure 3: Monthly Variation of Global Solar Radiation in 2009 - 2010 


\subsection{Seasonal Variation of Global Solar Radiation}

Figure 4 shows that the global solar radiation significantly fluctuates from season to season. The Pokhara region is part of the Mid Hill Terrain covering 64\% of area of Nepal. The measured solar energy for winter, spring, summer and autumn are 14.01, 19.90, 18.95 and 16.14 $\mathrm{MJ} / \mathrm{m}^{2} /$ day respectively. The maximum clear sky days are found in spring and minimum in winter.

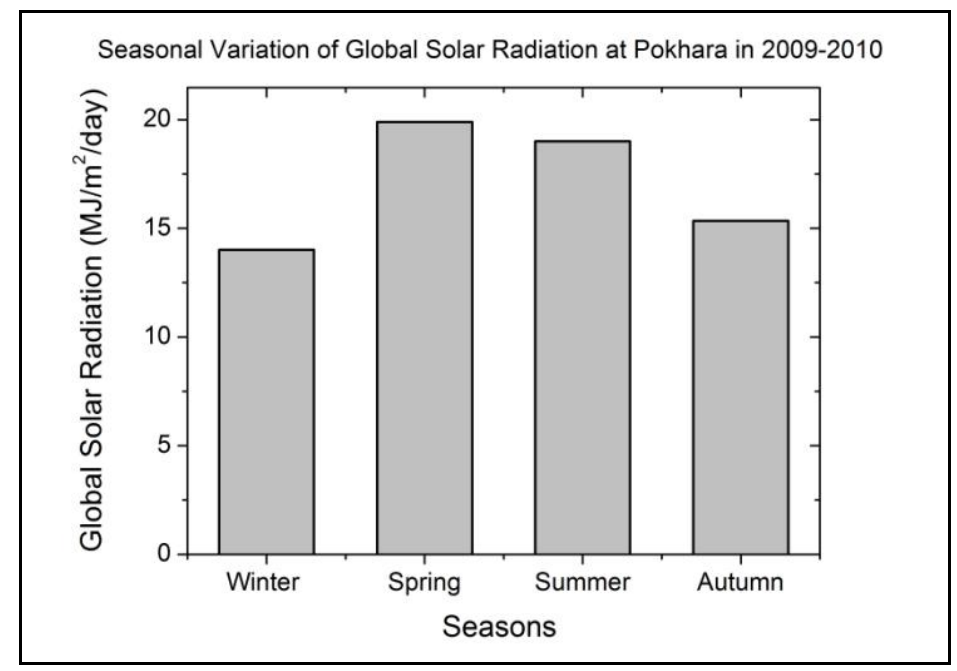

Figure 4: The Seasonal variation of Global Solar Radiation in 2009 and 2010

\subsection{Variation of Global Solar Radiation with Temperature in 2009-2010}

It is observed that the global solar radiation varies with temperature throughout the year except in the summer which sees significant rainfall in the Pokhara region as shown in the figure 5. The deviation of solar radiation from temperature in summer is primarily caused by the presence of cloud and precipitation.

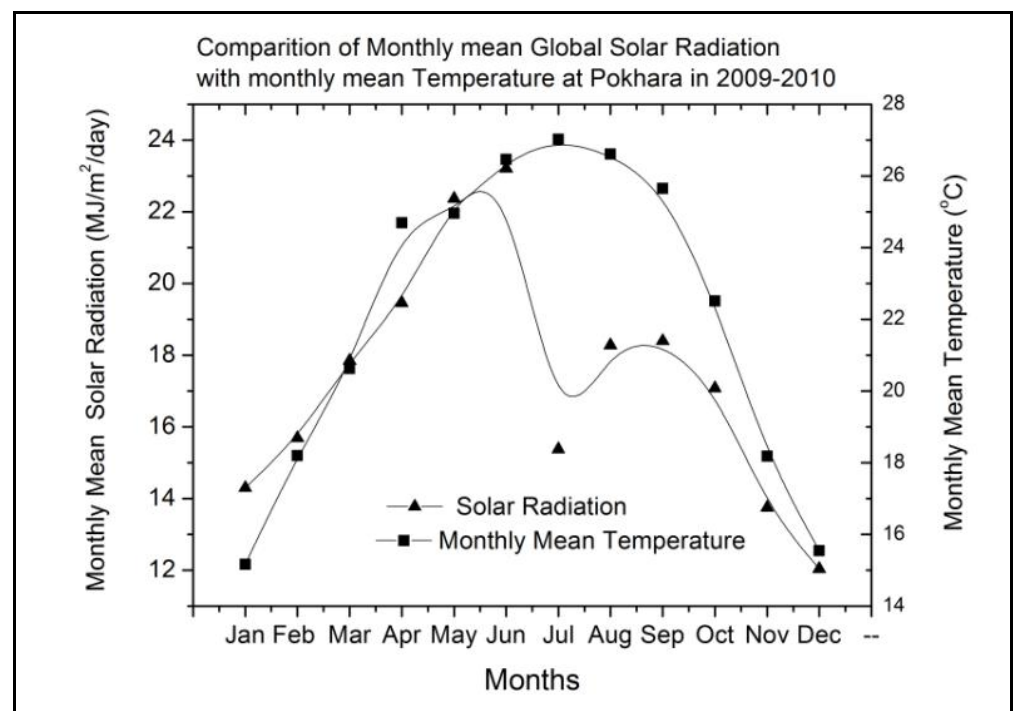

Figure 5: Variation of Global Solar Radiation with Temperature in 2009-2010 


\subsection{Variation of Global Solar radiation with Precipitation}

The variation of global solar radiation with respect to precipitation is shown in figure 6 . The distance of sun from the earth in this part is smallest during summer which should result in higher solar radiation. However, the presence of cloud and precipitation reduces the amount of solar radiation received at the ground level as evident from the figure plotted based on the measured data.

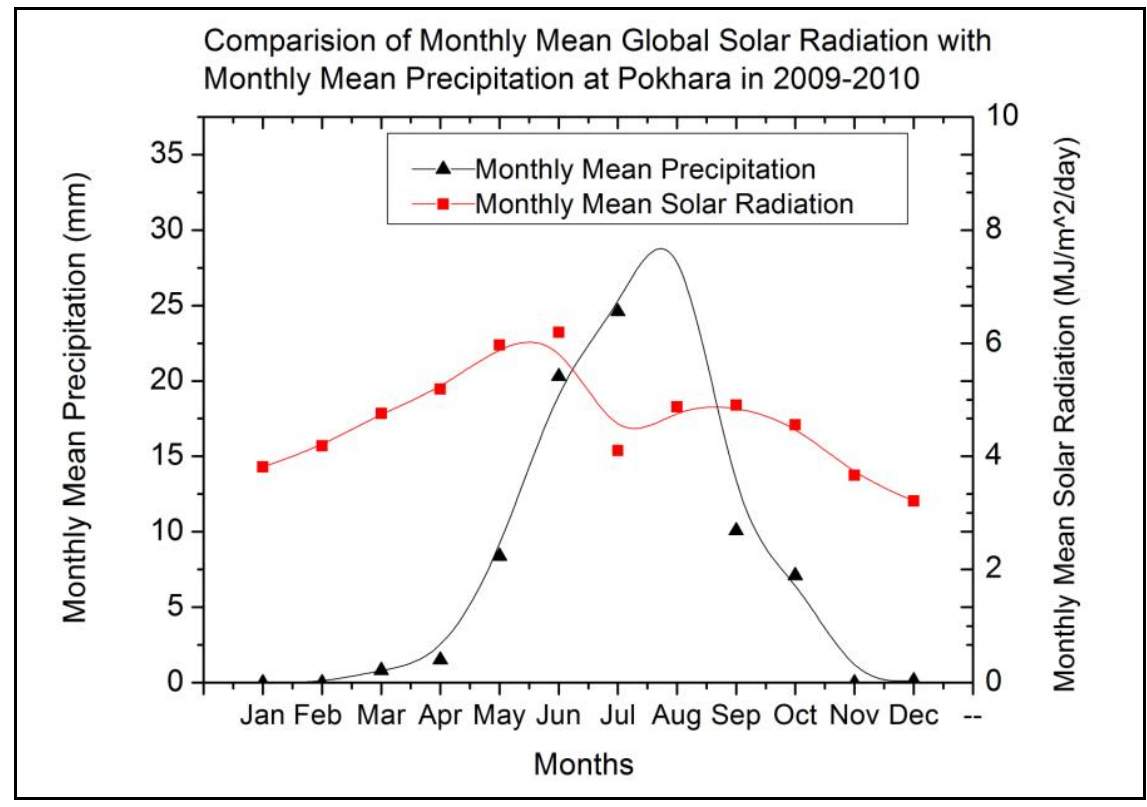

Figure 6: Variation of Global Solar radiation with Precipitation

\subsection{Relationship between Clearness Index (K), Cloud Transmittance Factor (cf) and measured Global Solar Radiation}

Monthly mean measured radiation, global extraterrestrial solar radiation, clearness index, cloud transmittance factor, temperature, relative humidity, rainfall and wind speed are presented in Table 1.

Figure 7 shows the relationship between global solar radiations (GSR), clearness index (K) and cloud transmittance factor (cf). The comparative graph as given in Figure 4 shows that the increasing and decreasing trend of GSR, $\mathrm{cf}$ and $\mathrm{K}$ are tentatively similar it means that there is strong correlation in between GSR, cf and K. Hence when we got some results cf then can predict the global solar radiation which will be the one of the best option in coming days. The given figure clearly indicates that there is maximum amount of solar energy can be harvested in spring and minimum in summer which is quite different than at other locations with different terrain [10].

The clearness index is defined as the ratio of measured global solar radiation $\left(\mathrm{H}_{\mathrm{g}}\right)$ to the extraterrestrial global solar radiation $\left(\mathrm{H}_{0}\right)$. Similarly the cloud transmittance factor is the ratio of measured radiation to the calculated clear sky radiation no aerosols, zero surface albedo. It is measured in percentage. Figure 3 shows that the coefficient of determination 0.70 is found in 
between clearness factor $\left(\mathrm{K}_{\mathrm{T}}\right)$ and cloud transmittance factor $(\mathrm{cf})$. It concluded that there was sufficient amount of energy is found even at the winter season.

Table 1: Relationship between Clearness Index (K), Cloud Transmittance Factor (cf) and measured Global Solar Radiation at Pokhara in 2009-2010

\begin{tabular}{|c|c|c|c|c|c|c|}
\hline Months & $\begin{array}{c}\mathrm{H}_{\mathrm{g}}, \\
\mathrm{MJ} / \mathrm{m}^{2} / \text { day }\end{array}$ & $\begin{array}{c}\mathrm{H}_{0}, \\
\mathrm{MJ} / \mathrm{m}^{2} / \text { day }\end{array}$ & $\mathrm{K}=\mathrm{H}_{\mathrm{g}} / \mathrm{H}_{0}$ & cf, \% & $\mathrm{T}_{\mathrm{av}},{ }^{\circ} \mathrm{C}$ & $\begin{array}{c}\text { Rainfall } \\
\mathrm{mm}\end{array}$ \\
\hline Jan & 14.30 & 21.64 & 15.17 & 0.5877 & 15.17 & 0.00 \\
\hline Feb & 15.69 & 26.06 & 18.20 & 0.5498 & 18.20 & 0.00 \\
\hline Mar & 17.85 & 31.84 & 20.63 & 0.4868 & 20.63 & 0.82 \\
\hline Apr & 19.46 & 37.43 & 24.69 & 0.4691 & 24.69 & 1.52 \\
\hline May & 22.37 & 40.83 & 24.96 & 0.6254 & 24.96 & 8.39 \\
\hline Jun & 23.21 & 42.2 & 26.46 & 0.6598 & 26.46 & 20.31 \\
\hline Jul & 15.38 & 41.94 & 27.02 & 0.5398 & 27.02 & 24.60 \\
\hline Aug & 18.28 & 40.95 & 26.61 & 0.5297 & 26.61 & 33.10 \\
\hline Sep & 18.40 & 39.24 & 25.65 & 0.5775 & 25.65 & 10.08 \\
\hline Oct & 17.08 & 37.06 & 22.51 & 0.647 & 22.51 & 7.10 \\
\hline Nov & 13.75 & 22.83 & 18.18 & 0.6195 & 18.18 & 0.00 \\
\hline Dec & 12.04 & 20.34 & 15.55 & 0.5994 & 15.55 & 0.14 \\
\hline
\end{tabular}

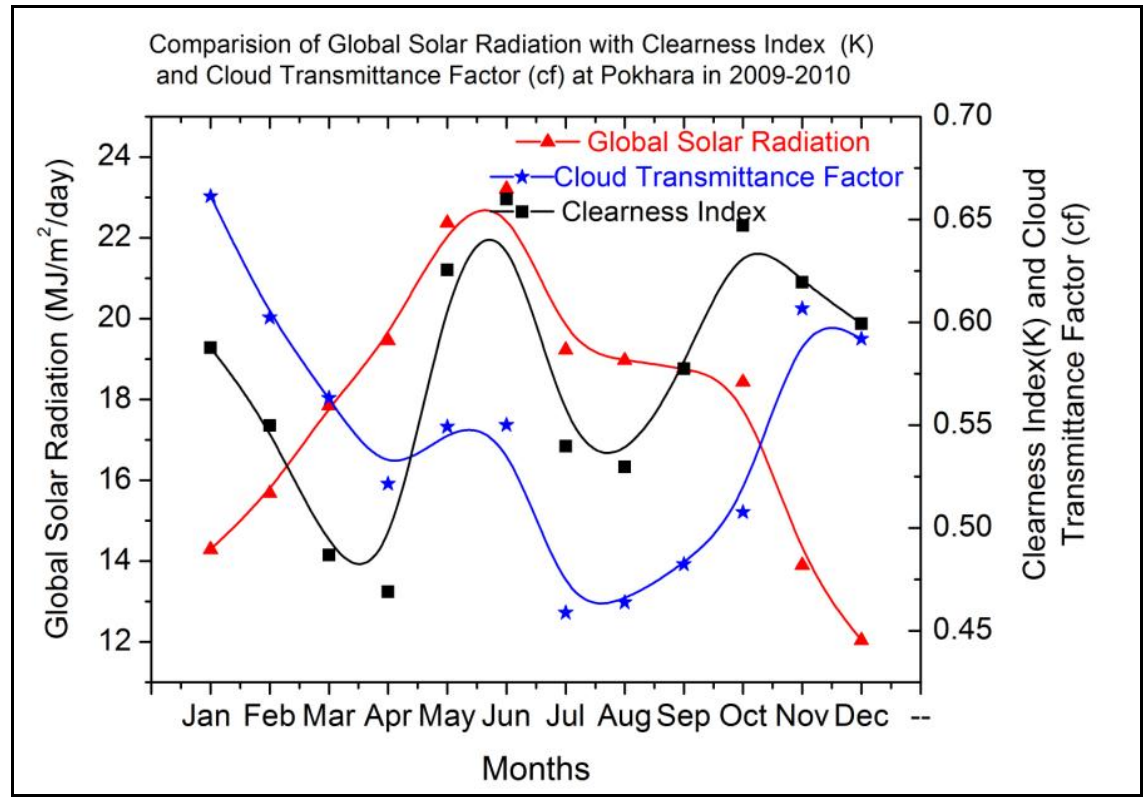

Figure 7: Correlation Coefficient in between Clearness Index K, Cloud transmittance Factor (cf), and global solar Radiation 


\section{Conclusion}

It is found that the daily average global solar radiation is $17.32 \mathrm{MJ} / \mathrm{m}^{2} / \mathrm{day}$ is found at Pokhara, which showed that such amount of energy is sufficient to promote off grid and grid connected solar photovoltaic (PV) for power generating plants at the Pokhara region. The global solar radiation varies with month to month and season to season including temperature and precipitation. Finally it is confirmed that the global solar radiation can be estimated on the basis of coefficient of determination, cloud transmittance factor and clearness index. The maximum and the minimum values of global solar radiation $20.47 \mathrm{MJ} / \mathrm{m}^{2}$ and 14.01 are found in spring and winter season at Pokhara. However there is low global solar radiation is measured in summer due to the excess rainfall at Pokhara. Hence the topography as well as local weather condition is also plays the vital role for the estimation of global solar radiation in any part of the world including Nepal. Finally it is confirmed that the global solar radiation can be estimated on the basis of coefficient of determination, cloud transmittance factor and clearness index.

\section{Acknowledgements}

Authors are grateful to express thanks to Solar Radiation and Aerosol in Himalaya Region (SAHR) project of IOE Pulchowk (Nepal) for providing the data of Pyranometer and other necessary supports. The support provided by the Prof. B. P. Pokharel, Prof. R.K. Sharma, Asso. Prof. N.P. Sharma, Prof. T.R. Bajracharya, Dr. B. Niraula, R.C. Poudel, M.C. Luintel and staffs of Department of Engineering Science and Humanities, Pulchowk Campus is highly acknowledged.

\section{References}

[1] Ibrahim, S. M. A. (1985). Predicted and Measured Global Solar Radiation in Egypt, Solar Energy, 35(2), 185-188.

[2] El-Sebaii, A. A., Al-Ghamdi, A. A., Al-Hazmi, F. S., Faidah, Adel S. (2009). Estimation of Global Solar Radiation on horizontal surfaces in Jeddah, Saudi Arabia, Energy Policy, 37, 3645-3649.

[3] WECS, Water and Energy Commission Secretariat (2010). Energy Synopsis Report, Government of Nepal.

[4] Sukhera, M. B. and Pasha, M. A. R. (1987). Solar Radiation Maps for Pakistan, Pakistan Solar and Wind Technology, 4(2), 229 -238.

[5] Becker, C. F., Boyd, J. S. (1957). Solar Radiation availability on Surfaces in United States Affected by Season, Orientation, Latitude, Altitude, and Cloudiness, Solar Energy, 1, 13-21.

[6] Iqbal, M. (1983). An Introduction to Solar Radiation, Academic Press, New York.

[7] SWERA (2006). United Nation Environment Program Global Environment Facility, Solar and Wind Energy Resource Assessment in Nepal.

[8] Poudyal, K. N., Daponte, P., Luca, D. V., Bhattarai, B. K., Sapkota, B. (2010). Study of Variation of Global Solar Radiation at different altitudes of Himalaya Region - A Case Study in Nepal, 17th Symposium IMEKO TC 4, 3rd Symposium IMEKO TC 19 and 15th IWADC Workshop, Instrumentation for the ICT Era, Kosice, Slovakia.

[9] Oki, M. and Shiina, H. (2003). Preliminary Study on an Estimation method for annual solar Irradiance at various geographical altitudes, Eighth International IBPSA Conference, Eindhoven, Netherlands, 11-14.

[10] Janjai, S. (2008). Assessment of Solar Energy Potentials for Cambodia. 
[11] Poudyal, K. N., Bhattarai, B. K., Kjeldstad, B and Sapkota, B. K., (2011). Solar Radiation Potential at Four Sites of Nepal, Journal of the Institute of Engineering, 8(3), 189-197.

[12] Kenichi, U. and Aryal, R. (2008). Impact of tropical convective activity on monthly Temperature variability during nonmonsoon season in the Nepal Himalayas, Journal of Geophysical Research, 113, D18112.

[13] Kipp and Zonen (2008).

[14] Høiskar, B. A. K., Haugen, R., Danielsen, T., Kylling, A., Edvardsen, K., Dahlback, A., Johnsen, B., Blumthaler, M., and Schreder, J. (2003). Multichannel, moderate -bandwidth filter instrument for measurement of the ozone-column amount, cloud transmittance, and Ultraviolet dose rates, Applied Optics, 42(18), 3472-3479.

[15] Duffie, J. A., and Beckman, W. A. (1991). Solar Engineering of Thermal Processes, 2nd Edition, John Wiley and Sons, New York. NY. 